This item was submitted to Loughborough's Research Repository by the author.

Items in Figshare are protected by copyright, with all rights reserved, unless otherwise indicated.

\title{
Effects of material morphology and processing conditions on the characteristics of hydroxyapatite and high-density polyethylene biocomposites by selective laser sintering
}

\section{PLEASE CITE THE PUBLISHED VERSION}

\section{PUBLISHER}

Professional Engineering Publishing / @ IMechE

\section{VERSION}

VoR (Version of Record)

LICENCE

CC BY-NC-ND 4.0

\section{REPOSITORY RECORD}

Hao, L., M.M. Savalani, Y. Zhang, K.E. Tanner, and Russell A. Harris. 2019. "Effects of Material Morphology and Processing Conditions on the Characteristics of Hydroxyapatite and High-density Polyethylene Biocomposites by Selective Laser Sintering". figshare. https://hdl.handle.net/2134/4703. 
This item was submitted to Loughborough's Institutional Repository (https://dspace.lboro.ac.uk/) by the author and is made available under the following Creative Commons Licence conditions.

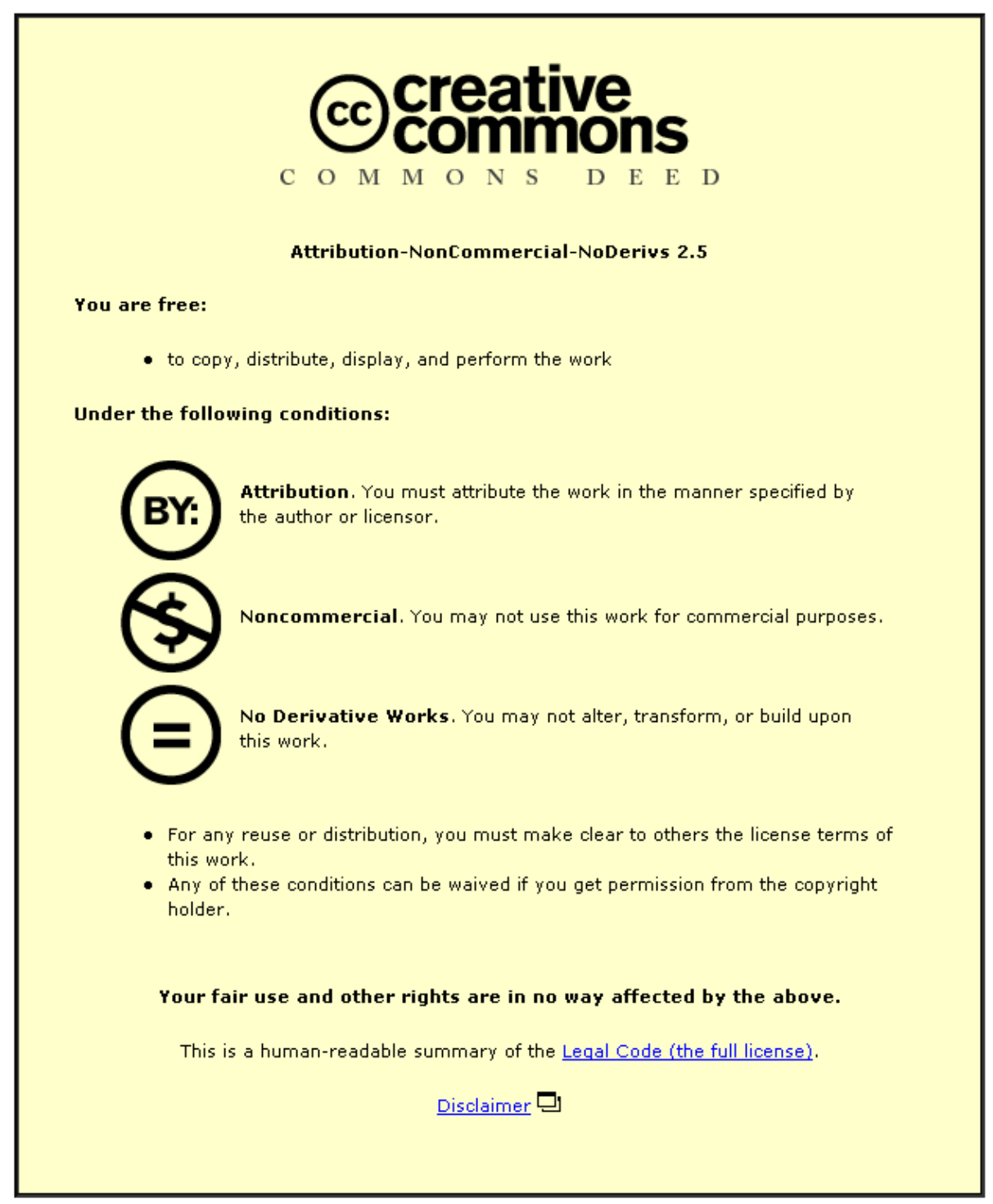

For the full text of this licence, please go to: http://creativecommons.org/licenses/by-nc-nd/2.5/ 


\title{
Effects of material morphology and processing conditions on the characteristics of hydroxyapatite and high-density polyethylene biocomposites by selective laser sintering
}

\author{
L Hao $^{1 *}$, M M Savalani ${ }^{1}$, Y Zhang ${ }^{2}$, K E Tanner ${ }^{2}$, and R A Harris ${ }^{1}$ \\ ${ }^{1}$ Rapid Manufacturing Research Group, Wolfson School of Mechanical and Manufacturing Engineering, Loughborough \\ University, Loughborough, Leicestershire, UK \\ ${ }^{2}$ Department of Materials, Queen Mary University of London, London, UK
}

The manuscript was received on 9 February 2006 and was accepted after revision for publication on 4 July 2006.

DOI: $10.1243 / 14644207 J M D A 92$

\begin{abstract}
Hydroxyapatite (HA), a ceramic to which bone inherently bonds, incorporated into a polymer matrix enhances the bioactivity of implants. In order to rapid-manufacture bioactive implants, selective laser sintering (SLS) has been used to fabricate HA and high-density polyethylene (HDPE) composite (HA-HDPE). The properties of SLS-fabricated specimens have been investigated. The main aspects to be considered in the SLS technology are the properties of the materials used in the process and processing parameters (PPs). HA-HDPE composite specimens have been fabricated using five different powders with variations in particle size (PS), PS distribution, and five different laser PPs. The sintering height, the width, and the shrinkage of the specimens were determined and the effects of the particles and PPs on the physical properties were investigated. The HA-HDPE specimens were found to be highly porous and the sintered density and porosity of the specimens were influenced by the PS and PPs. The interparticle connectivity and the pore size range of the specimens were found to be predominantly determined by the PS and to a lesser extent also influenced by the PPs. The strength of these specimens and the relationship with porosity are discussed.
\end{abstract}

Keywords: selective laser sintering, hydroxyapatite, polyethylene, bioactive implants, tissue scaffolds

\section{INTRODUCTION}

Selective laser sintering (SLS) is a technique of selectively sintering sequential layers of powder to form the desired object. Solidification of the loosely compacted powder is obtained by fusion via the thermal energy supplied by a laser beam [1]. The powder that is struck by the beam is melted, fuses with the adjacent particles, and then resolidifies, whereas the other areas of powder remain dissociated. Successive layers of powder are deposited and scanned by the

\footnotetext{
*Corresponding author: Rapid Manufacturing Research Group, Wolfson School of Mechanical and Manufacturing Engineering, Loughborough University, Loughborough, Leicestershire LE11 3TU,UK.email: l.hao@lboro.ac.uk
}

laser, one on top of the other. Each sintered layer bonds to the previous layer; eventually, an entire component is built. SLS can be used to process a variety of materials, provided they are available as powder and that the powder particles tend to fuse or sinter when heat is applied. Powders that have lower fusion or sintering properties can be lasersintered by adding a binder material, typically a polymer, to the basic powder. In order to produce suitable products, the main aspects to be considered in the SLS technology are the properties of the powders used in the process and processing parameters (PPs). It is important to obtain a better understanding of the relationship between powder properties, fabrication parameters in the SLS process, and the parts produced using this process. Gibson and 
Shi [2] demonstrated that the material properties play an important role in determining the optimal fabrication parameters and that both material properties and fabrication parameters have a major influence on the mechanical properties (e.g. tensile strength, surface hardness, and density), dimensional accuracy, and surface qualities (i.e. roughness) for SLS-fabricated polymer parts. Studies on the laser sintering of iron powder showed that the processing parameters such as laser power, scan rate, scan line spacing, thickness of layer, and scanning geometry and sintering atmosphere [3] and the characteristics of the powder material such as particle size (PS) and PS distribution [4] affect the densification behaviour and the attendant microstructural features. Shi et al. [5] investigated the effect of the material properties of the polymer on the quality of SLS parts and found that the PS of the powder affected not only the precision, but also the density of the SLS-fabricated parts.

As the powders are subjected to low compaction forces during their deposition to form new layers, SLS-fabricated objects are usually porous. This interconnected porosity is a key property requirement in biomedical applications, including artificial bones and tissue engineering scaffolds. The nature and extent of this interconnected porosity can be tailored and controlled effectively to meet different application criteria through material selection and physical design, and owing to the additive nature of the SLS process, control over internal structure is possible. Manufacturing porous implants through which blood vessels and bone could grow (thus integrating the implant into the body) would remove the risk of implant extrusion, which may occur with conventional implants. This deliberate and controlled porosity would further mean that even if the initial strength and the toughness were below than those required for long-term use, the bone ingrowth would increase the strength of the bone-implant composite by a factor of 3 or 4 [6], bringing it to acceptable levels. The porosity also offers an opportunity during post-processing to introduce additional materials into the object to alter material composition as well as help control part stability. Polymethyl methacrylate-coated calcium phosphate powders have been successfully processed via SLS and subsequent post-processing to produce strong porous structures [7]. Das et al. [8] investigated the design and fabrication of scaffolds with periodic cellular and biomimetic architectures using nylon and built cubes with $0.8 \mathrm{~mm}$ channels and $1.2 \mathrm{~mm}$ pillars. Williams et al. [9] computationally designed and SLS-fabricated scaffolds of polycaprolactone, a bioresorbable polymer, with the smallest pores being $1.75 \mathrm{~mm}$ in diameter. Tan et al. [10] and Chua et al. [11] found micropores formed within the scaffold structure produced via SLS from physically blended hydroxyapatite (HA)/polyetheretherketone and HA/polyvinyl alcohol composites. Cruz et al. [12] showed internal porosity with $150 \mu \mathrm{m}$ average pore size in the SLS-fabricated HA/poly(L-lacide) specimens. Leong et al. [13-15] investigated the effects of key SLS parameters on the control of porosity and porous microstructure of polymeric matrix drug delivery devices and found that the laser power showed a linear relationship between porosity and variation in parameter values; scan speed revealed an inconsistent relationship with porosity; and the average porosity had an inverse linear relationship with part-bed temperature.

However, little work has been conducted to study the effects of original material properties on the characteristics of SLS-fabricated parts using polymer/ceramic biocomposites. HA particulate reinforced high-density polyethylene (HDPE) composite (HA-HDPE), with 40 volper cent HA $\left(\mathrm{HAPEX}^{\mathrm{TM}}\right)$, has been developed by Bonfield et al. $[16,17]$ and used clinically for bone augmentation for over 15 years [18]. The combination of bioactive, stiff, but brittle HA and low modulus, ductile HDPE gives the composite good biocompatibility and adequate mechanical properties. HA is a ceramic to which bone bonds and its volume ratio in HAHDPE composites determines the bioactivity of the composite. Previous work [19] has evaluated the performance of $\mathrm{CO}_{2}$ and $\mathrm{Nd}$ :YAG lasers and revealed the influence of PSs on the operation window for laser sintering of HA-HDPE. By using five different powders with variations in PS, PS distribution, and laser PPs, this study investigates the effects of powder morphology and PPs on the SLS of HA-HDPE materials and discusses how these factors govern the characteristics of sintered specimens in terms of interparticle connectivity, porosity, and strength. It has been found that powder plays an important role in the characteristics of the sintered specimens and can, therefore, be varied to control the property of the HA/polymer composites by SLS.

\section{METHODS}

\subsection{HDPE, HA raw materials, and HA-HDPE composite powders}

The HDPE (Rigidex HM4560XP) was supplied by BP Chemicals Ltd in the pellet form and synthetic HA particles (P218R, Plasma Biotal Ltd, UK) were used as the filler material for preparing $40 \mathrm{vol}$ per cent HA-HDPE composites. The HA particles had a median size $\left(d_{0.5}\right)$ of $3.80 \mu \mathrm{m}$. The composite production process is described in greater detail by Wang et al. [20], but briefly, the HA and HDPE 
powders were blended to produce mixtures with different compositions. The mixture of $\mathrm{HA}$ and HDPE, at 40 vol per cent HA, was compounded in a twin screw extruder (Betol BTS40L, Betol, Luton, UK) to produce HA-HDPE composites. The extruded composite was subsequently pelletized in a Betol pelletizer. The pelletized HA-HDPE composite was powderized in an ultra centrifuge mill (Retsch Powderizer, Germany), using a sieve of $0.120 \mathrm{~mm}$ aperture size. Liquid nitrogen was used as a coolant to enbrittle the composite and to prevent temperature increases during milling. The powders produced are not a discrete mixture, but composite powders in which individual powder particles contain both the matrix and the filler material.

The resultant particles were then sieved. Sieves with apertures sizes of 50, 75, and $106 \mu \mathrm{m}$ were stacked from largest to smallest to obtain powders with PS of $0-50,50-75$, and $75-106 \mu \mathrm{m}$. The sieves with 75 and $106 \mu \mathrm{m}$ aperture sizes were used individually to get powders with PS of $0-75$ and $0-106 \mu \mathrm{m}$, which have relatively large PS distributions and are considered as a mixture of powders with different PS (i.e. powders of $0-50,50-75$, and $75-106 \mu \mathrm{m}$ combined to provide powders of $0-106 \mu \mathrm{m}$, the ratio of particles was quantified by weight). In total, five powders with different PS distributions were obtained.

\subsection{SLS experimental systems and processing}

Often a trial-and-error method is adopted to obtain suitable fabrication parameters to satisfy the demand of specific applications. Default fabrication parameters in commercial SLS systems, recommended by the manufacturer for a specific powder, do not satisfy the demands of all applications [2]. Hence, an experimental system has been produced, allowing greater control of fabrication parameters and the ability to incorporate different laser systems. The experimental SLS system incorporates an experimental powder bed chamber and a $\mathrm{CO}_{2}$ laser system (Synrad, Ltd, USA), as shown schematically in Fig. 1. The chamber consists of powder building and feeding cylinders, each $103 \mathrm{~mm}$ in diameter, a powder deposition system, and heater and temperature measurement devices. The chamber is contained within a polycarbonate box in conjunction with computer control station to provide an appropriate contained environment with an automated building platform and parameter control of the processing.

Leong et al. [13] found that the laser power and the scanning speed were key PPs to control the porosity of a porous polyamide drug delivery matrix and Ho et al. [21] showed that the energy density affected

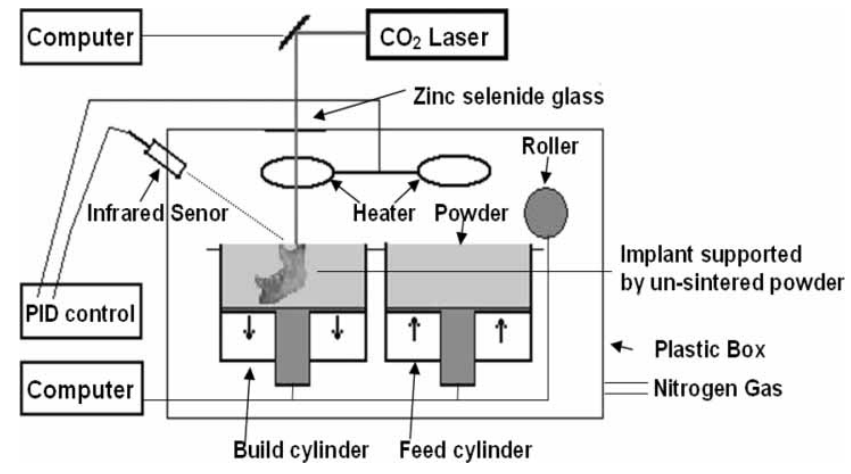

Fig. 1 Schematic representation of the experimental system for SLS biocomposite powders

the density of SLS polycarbonate. This study aims to investigate the effect of these key PPs on the characteristics of SLS-fabricated HA-HDPE specimens. On the basis of the operation window of SLS HA-HDPE powders prepared by milling with $250 \mu \mathrm{m}$ aperture and preliminary experiments on single-layer sintering of the powder particles [22], the PPs of interest were selected as shown in Table 1. The laser power was chosen as the main PP to be varied because it has been shown to provide better control over porosity when compared with other parameters [13]. Before laser sintering, the powders are prelayered and preheated by the overhead heater to $120^{\circ} \mathrm{C}$, i.e. $16{ }^{\circ} \mathrm{C}$ below the HA-HDPE melting temperature of $136{ }^{\circ} \mathrm{C}[22]$. The output of the heater was controlled to maintain the powder bed temperature, according to the temperature measured by the infrared sensor. The preheating of the powder helps to lower the energy required from the laser and ensures the stability of the processed parts during the sintering process $[\mathbf{2 3}]$.

The HA-HDPE specimens consist of six SLS layers with $0.15 \mathrm{~mm}$ layer thickness of powder deposition. The powder bed temperature, layer thickness, laser focus spot size, and laser scan space were consistent to sinter five different powders using five different laser PPs of PP0, PP1, PP2, PP3, and PP4, as shown in Table 1. PP0 and PP2 have the same

Table 1 Sintering parameters for the SLS of HA-HDPE powders with different PS ranges and distributions

\begin{tabular}{lcccccc} 
Sample size & \multicolumn{7}{c}{$3 \mathrm{~mm}$ width and $22 \mathrm{~mm}$ length } \\
Powder bed temperature $\left({ }^{\circ} \mathrm{C}\right)$ & \multicolumn{5}{c}{120} \\
Layer thickness $(\mathrm{mm})$ & \multicolumn{5}{c}{0.15} \\
Laser focus spot size $(\mu \mathrm{m})$ & \multicolumn{5}{c}{193} \\
Laser scan space $(\mu \mathrm{m})$ & \multicolumn{5}{c}{63.33} \\
Laser process parameters & PP0 & PP1 & PP2 & PP3 & PP4 \\
Laser power $(\mathrm{W})$ & 1.2 & 2.4 & 3.6 & 4.8 & 6.0 \\
Scanning speed $(\mathrm{mm} / \mathrm{s})$ & 1200 & 3600 & 3600 & 3600 & 3600 \\
Energy density $\left(\mathrm{KJ} / \mathrm{m}^{2}\right)$ & 15.8 & 10.5 & 15.8 & 21.1 & 26.4
\end{tabular}


energy densities, but different laser powers and scanning speeds, whereas PP1 to PP4 have the same scan speed but increasing laser power and thus energy input. Three replicate samples were built at each PP.

\subsection{Characterization}

The dimensions and weight of the SLS specimen samples were measured by Vernier callipers and a balance, respectively. Three measurements were conducted for each factor and the mean value was recorded. The particles of HA-HDPE composite powders and surface morphologies of specimens were examined using a scanning electron microscope (SEM) (LEO 440, UK). All samples were sputter coated with gold prior to examination.

\section{RESULTS AND DISCUSSION}

\subsection{HA-HDPE composite powders with different PSs and distributions}

Five different HA-HDPE composite powders are shown in Fig. 2. Most of the powder particles are irregular and elongated in shape. The primary difference among these five powders is their PS and distribution. The PS and distribution increased from the particles of $0-50,0-75$, and $0-106 \mu \mathrm{m}$, whereas the particles of 50-75 and 75-106 $\mu \mathrm{m}$ had a relatively

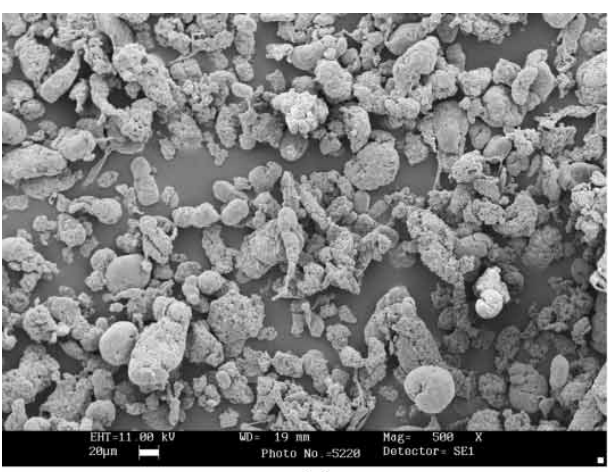

(a)

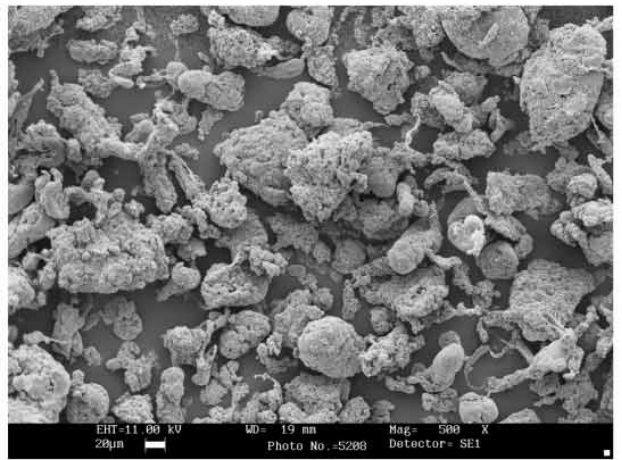

(c)

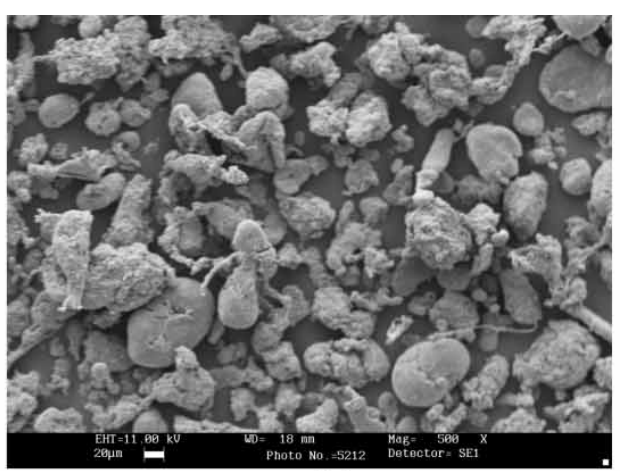

(b)

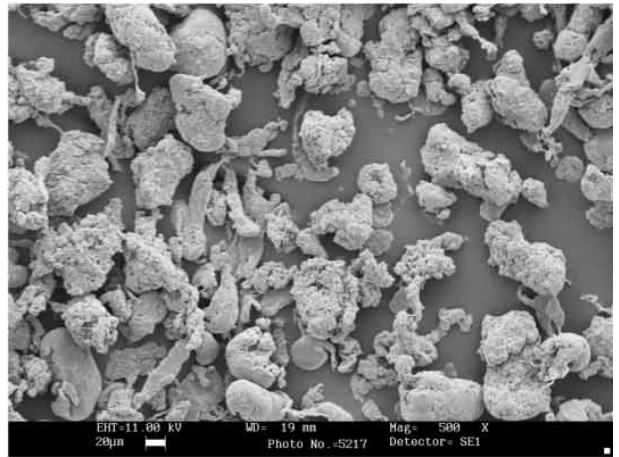

(d)

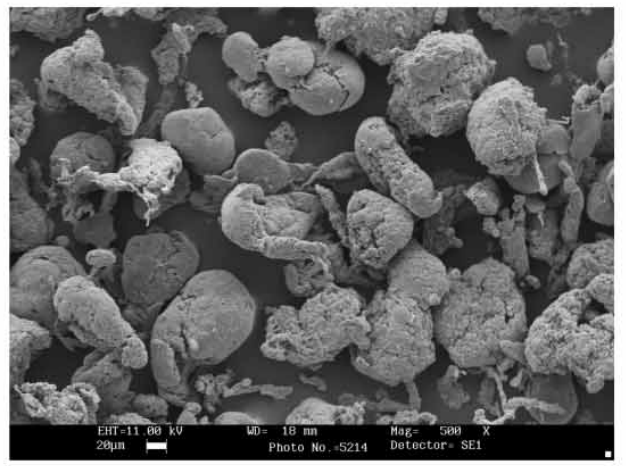

(e)

Fig. 2 SEM images of HA-HDPE powders sieved to different size range (a) $0-50 \mu \mathrm{m}$,

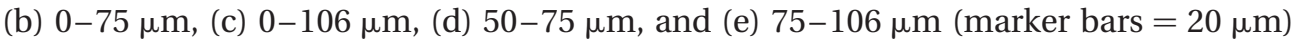


narrow particle distribution. The weight percentages of $0-50,50-75$ and $75-106 \mu \mathrm{m}$ particles in the particles of $0-106 \mu \mathrm{m}$ are 42,34 , and 24 per cent, respectively.

\subsection{Physical characteristics of the SLS HA-HDPE specimens}

\subsubsection{Sintering height of the specimens}

In a study of the sintering height/depth of powders following single time laser scanning, the laser power and the scanning speed have been shown to be directly related to the amount of energy delivered to the powder surface [24]. The energy density increases with laser power and decreases with scanning speed for the same scan spacing. The sintered heights of HA-HDPE six-layer specimens using various PPs and powder particles have been measured. As can be seen in Fig. 3, the sintered heights of all the fabricated specimens are greater than the total thickness value of six layers $(6 \times 0.15=0.9 \mathrm{~mm})$, showing that the laser sintering or penetration depth is greater than the layer thickness. For the same powder particles, the sintering height of the laser-sintered specimen increases with the energy

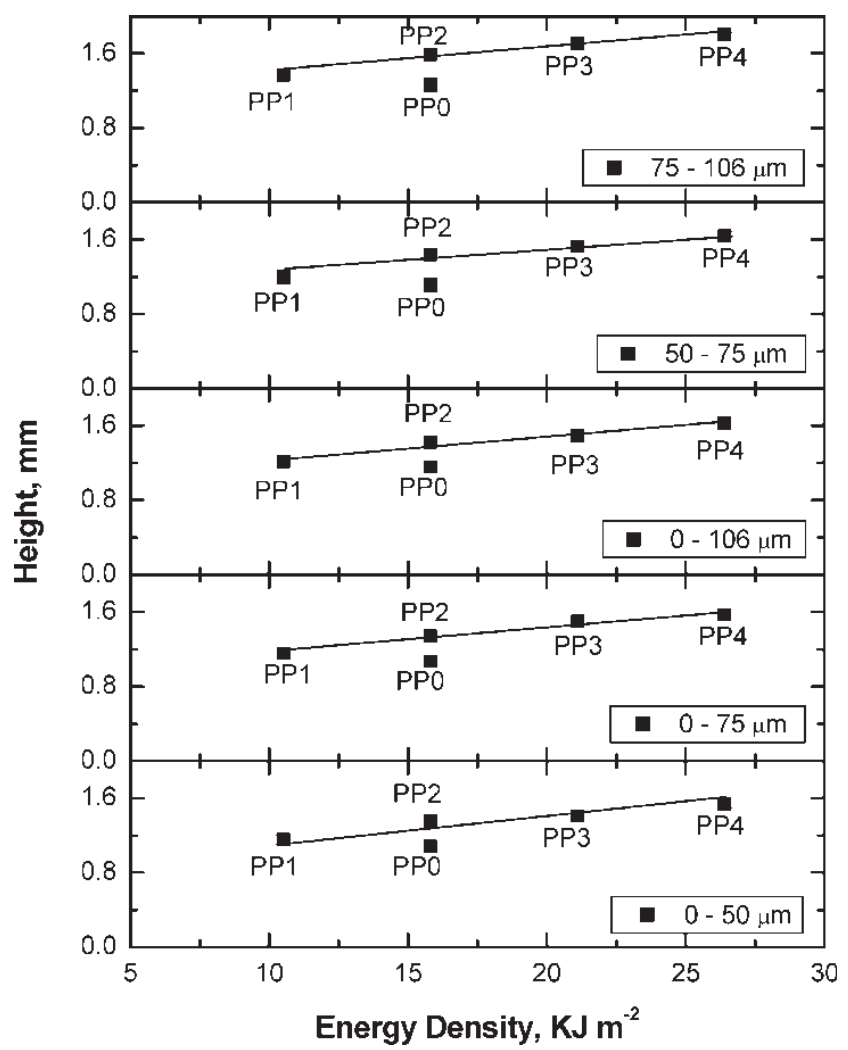

Fig. 3 The relationship between the sintering height of HA-HDPE specimens and energy density and PPs for different particle size distributions density at the same scanning speed for the PPs PP1 through PP4. This result indicates that at the same laser and powder interaction time, the increased heat generated by the higher energy density was transferred to powders and consequently leads to greater sintering depth. Although the energy density for PP0 conditions is the same as that for PP2 conditions and greater than that for PP1 conditions, the sintering depth of the specimens manufactured using PP0 conditions is markedly lower than that using PP2 or PP1 conditions. The higher laser power used at the PP2 and PP1 conditions would have greater heat induction rate and penetration, thus allowing greater sintering depth for each layer.

PS also influences the sintered height of the specimen (Fig. 3). For PP1 conditions, the sintered height of the specimens manufactured using the $0-50 \mu \mathrm{m}$ particles was less than those manufactured using 0$106 \mu \mathrm{m}$ particles, whereas the sintered height of the specimens manufactured using $50-75 \mu \mathrm{m}$ particles was less than those manufactured using 75-106 $\mu \mathrm{m}$ particles. Larger particles resulted in increased specimen height. Generally, similar results are found for the interaction between specimen height and PS at PP0, PP2, PP3, and PP4 conditions. It is more likely that the smaller particle powders experience greater densification because of the increased sintering activity for finer powders [4] and thereby a relatively higher shrinkage in the vertical direction.

\subsubsection{Width and shrinkage of the specimens}

A schematic diagram of the heat transfer in the powders following laser sintering (Fig. 4) shows that the heat dissipating from the powders in the scanned area to that in the non-scanned area through the boundary enhances the temperature of the neighbouring non-scanned powders to the melting temperature and thereby sinters these powders. As shown in Fig. 5, both surface width and length of the sintered specimens are greater than the laser scanning dimensions of $3 \mathrm{~mm}$ width and $22 \mathrm{~mm}$ length. The

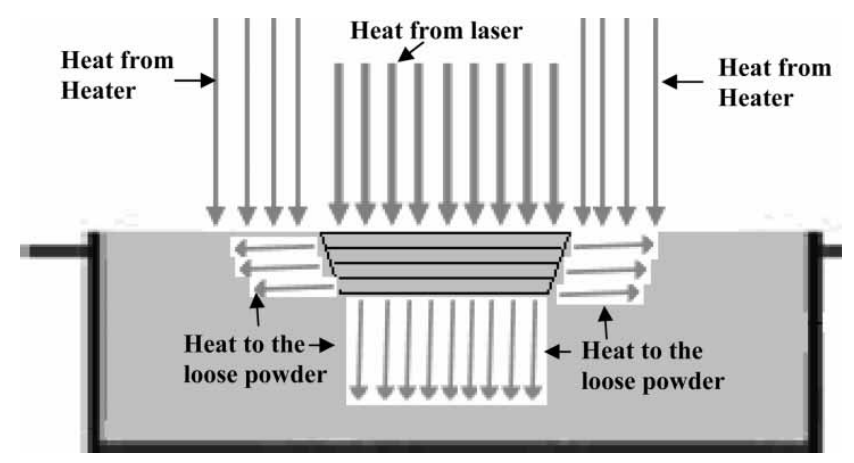

Fig. 4 A schematic diagram of the heat transfer processes in the laser sintering of the powders 


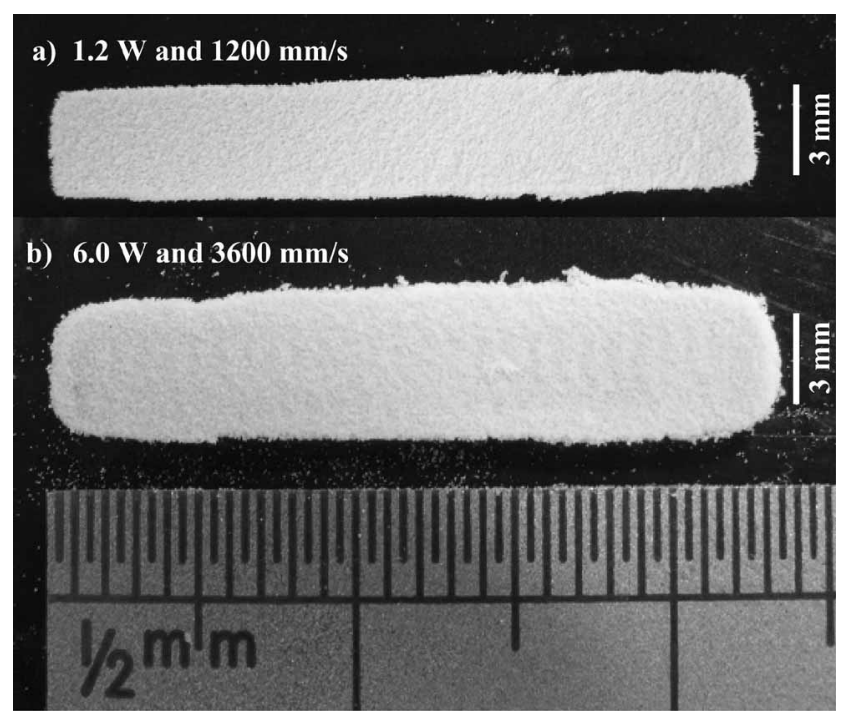

Fig. 5 The surface view of the specimens sintered at (a) laser power of $1.2 \mathrm{~W}$ and scanning speed of $1200 \mathrm{~mm} / \mathrm{s}$ and (b) laser power of $6.0 \mathrm{~W}$ and scanning speed of $3600 \mathrm{~mm} / \mathrm{s}$ (the scan area was $3 \mathrm{~mm}$ by $22 \mathrm{~mm}$ )

amount of sintered powders at neighbouring nonscanned area is shown by the difference between the width of the sintered specimen and scanning dimension of $3 \mathrm{~mm}$. All the laser-sintered specimens are wider and longer than the laser scanning dimension (Fig. 6).

For the same powder particles, the width of the laser-sintered specimens generally increases with the energy density at the same scanning speed. This result indicates that the greater heat generated by the higher laser energy is transferred from the laser scanned powders to the non-scanned neighbouring powders and thereby additional sintering occurs. In addition, the higher laser power but shorter interaction time at higher scanning speed used in PP2 conditions allows faster heat transfer to the sintered powder and thus quicker heat induction to the non-scanned neighbouring powders, which could cause greater temperature increases, whereas PP0 displays the opposite behaviour. Hence, more surplus boundary powders were sintered at PP2 conditions when compared with PP0 conditions.

The side views of the sintered specimens show that the specimens are narrower at the bottom than at the top (Fig. 7). Thus, shrinkage would have occurred during the laser sintering processing and the layers at the bottom and top of the specimen might experience different shrinkage rates. As the temperature of the scanned powders should be higher than that of the non-scanned powders, thermal shrinkage would occur in the sintered layer. Also, the temperature of the most recent deposited layer would be

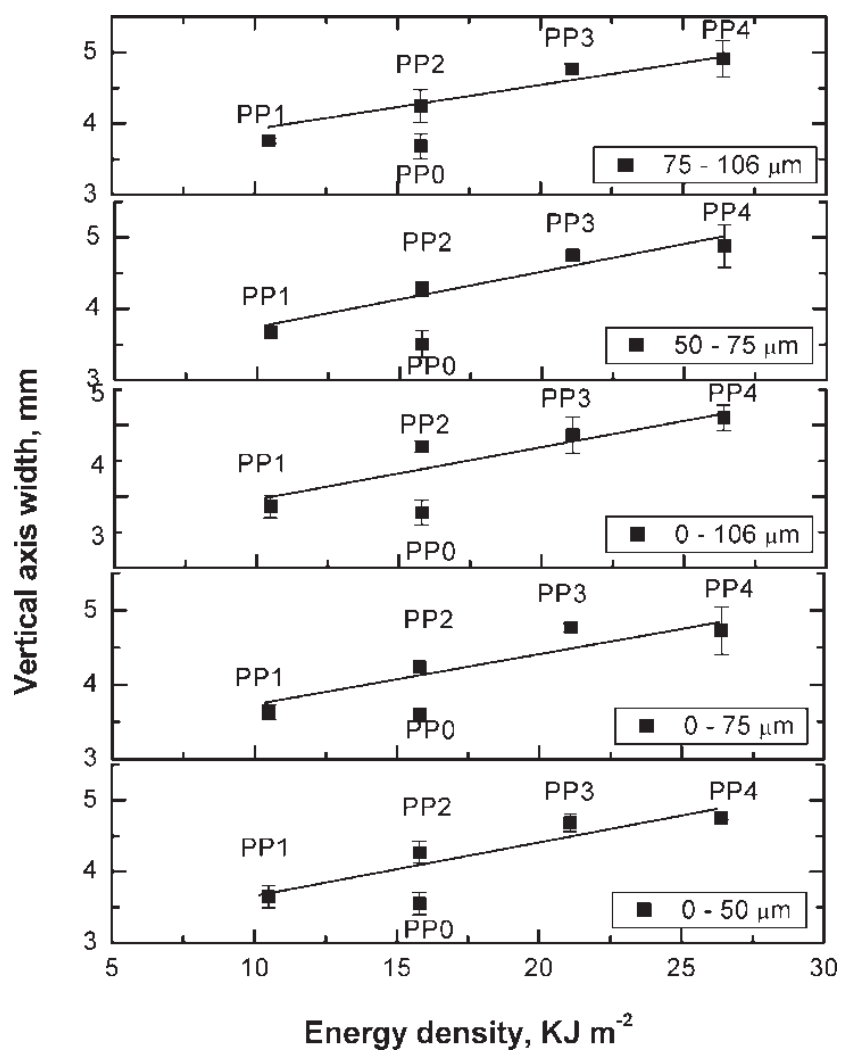

Fig. 6 The relationship between the width of HAHDPE specimens and energy density and PPs (the measurement of the width taken at the centre area of the specimen surface) for different PS distributions

higher than that of the previous layers, but will be heated for less time, thus different shrinkage rates occur [23]. As shown in Fig. 4, the specimen is supported by the non-sintered powders. The
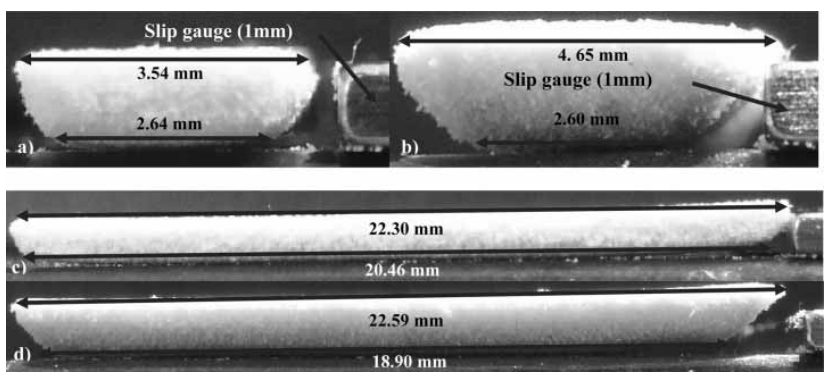

Fig. 7 The specimens (using particles of $0<$ PS $<50 \mu \mathrm{m}$ ) showing side views sintered at (a) laser power of $1.2 \mathrm{~W}$ and scanning speed of $1200 \mathrm{~mm} / \mathrm{s}$ and (b) laser power of $6.0 \mathrm{~W}$ and scanning speed of $3600 \mathrm{~mm} / \mathrm{s}$ and length views sintered at (c) laser power of $1.2 \mathrm{~W}$ and scanning speed of $1200 \mathrm{~mm} / \mathrm{s}$ and (d) laser power of $6.0 \mathrm{~W}$ and scanning speed of $3600 \mathrm{~mm} / \mathrm{s}$ 
temperature of the first sintered layer increased after laser scanning and might be much higher than that of the unsintered supporting powders, thus this layer experiences thermal shrinkage. When another powder layer is deposited on this layer and sintered, the temperature of the newly sintered layer is presumably higher than that of the previous layer. This temperature difference causes the newly scanned layer to shrink. In addition, the heat transferred from the newly laser scanned layer to the previously sintered layer may increase the temperature difference between the previous layer and supporting non-sintered powders. Again, this caused shrinkage of the previously sintered layer. This phenomenon is repeated when the next layer is sintered. Hence, the bottom part of the specimen would have experienced repeated heating - shrinkage cycles and consequently greater shrinkage than the top.

The phenomenon of shrinkage also exists in the commercial laser sintering systems for the same reasons, again leading to thermal imbalance and shape distortion during the sintering process. In order to minimize the shape distortion caused by shrinkage, two approaches can be used: one is to adjust the build conditions and the other is to make some allowances to compensate for the distortion [23]. To compare the shrinkage of the specimens, the shrinkage ratio is defined as the ratio of the width of the bottom and top layers and lower shrinkage ratios indicate greater difference between the width of the bottom and top layers. The shrinkage ratio generally decreases with increasing energy density for the PPs PP1 through PP4 (Fig. 8). The specimens fabricated using PP0 conditions have higher shrinkage ratios than those produced using PP2 conditions. This effect is probably because PP0 conditions provide a lower heat induction rate and a longer interaction time, allowing the temperature differences between the layers and the sintered layer and unsintered powders to even out. Although the characteristics of particle powders do not bring about substantial differences in the shrinkage between the bottom and surface layers, they do play a significant role in shrinkage.

\subsection{Density and porosity of the SLS HA-HDPE specimens}

The sintered density of a specimen is defined as the ratio of weight to volume. The volume of the specimens was calculated using the average widths and lengths of the top and bottom surfaces. As shown in Fig. 9, for the $0-50$ and $0-75 \mu \mathrm{m}$ particles, the sintered density of the specimen increases with increasing energy density for the PPs PP1 through PP4. The higher energy density results in more of the binder

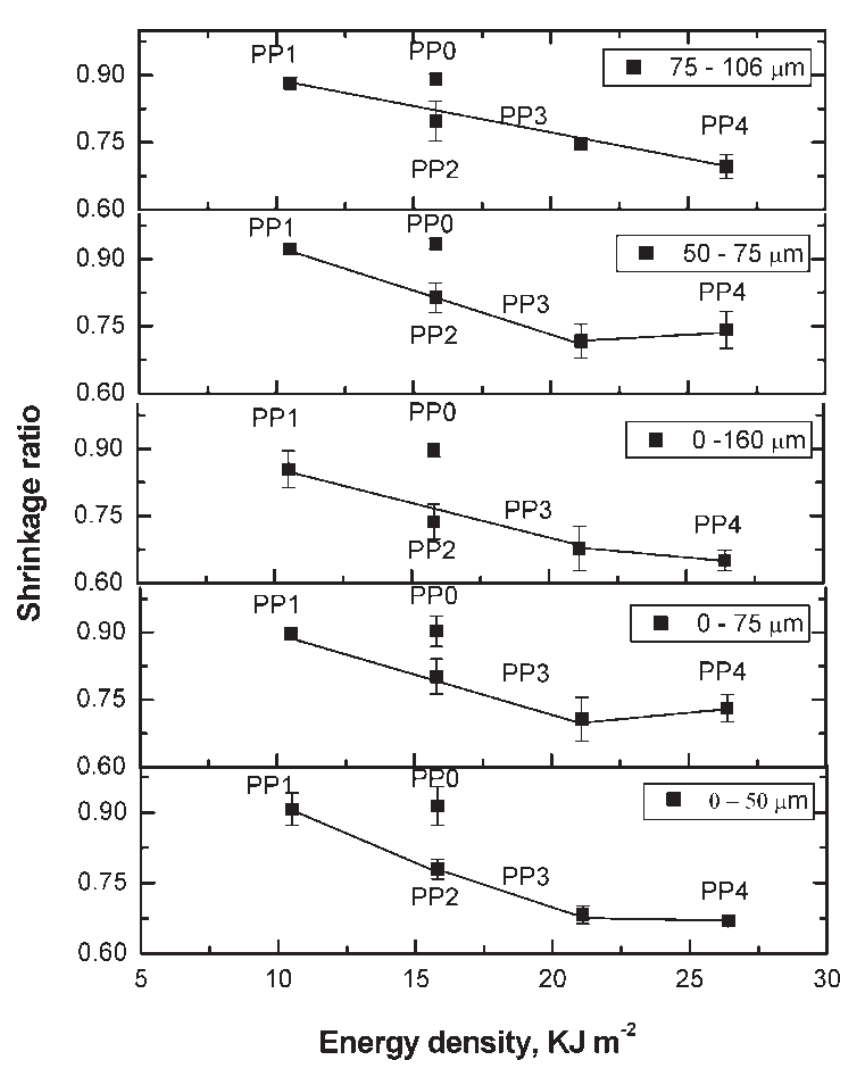

Fig. 8 The relationship between the shrinkage ratios of HA-HDPE specimens and energy density and PPs for different PS distributions

polymer melting and, consequently, greater densification. Previous studies revealed that the sintered density of the laser-sintered polycarbonate [21] and iron powder [3] increased with the energy density until a critical energy input is reached. However, the relationship between the energy density and the sintered density of the specimens using $0-106$, $50-75$, and $75-106 \mu \mathrm{m}$ particles is non-linear (Fig. 9). This non-linearity may be because the large and irregular particles would result in inhomogenous initial packing of the deposited powders when the layer thickness is $0.150 \mathrm{~mm}$ and thus not large enough to spread out these large powder particles evenly. In general, the sintered density of the specimens fabricated at PP0 conditions is close to those fabricated at PP2 conditions for all powder particles (Fig. 9), indicating that the energy density plays a predominant role in the sintered density, despite different laser powers and scanning speeds.

At the same laser parameters, the average sintered density of the specimens with $0-50 \mu \mathrm{m}$ particles is higher than that of $0-75 \mu \mathrm{m}$ particles. For instance, at $\mathrm{PP} 1$ conditions, the sintered density is $0.48 \mathrm{Mg} / \mathrm{m}^{3}$ for the specimen with $0-50 \mu \mathrm{m}$ particles and $0.43 \mathrm{Mg} / \mathrm{m}^{3}$ for that with $0-75 \mu \mathrm{m}$ particles. Finer powders have generally greater surface area, 


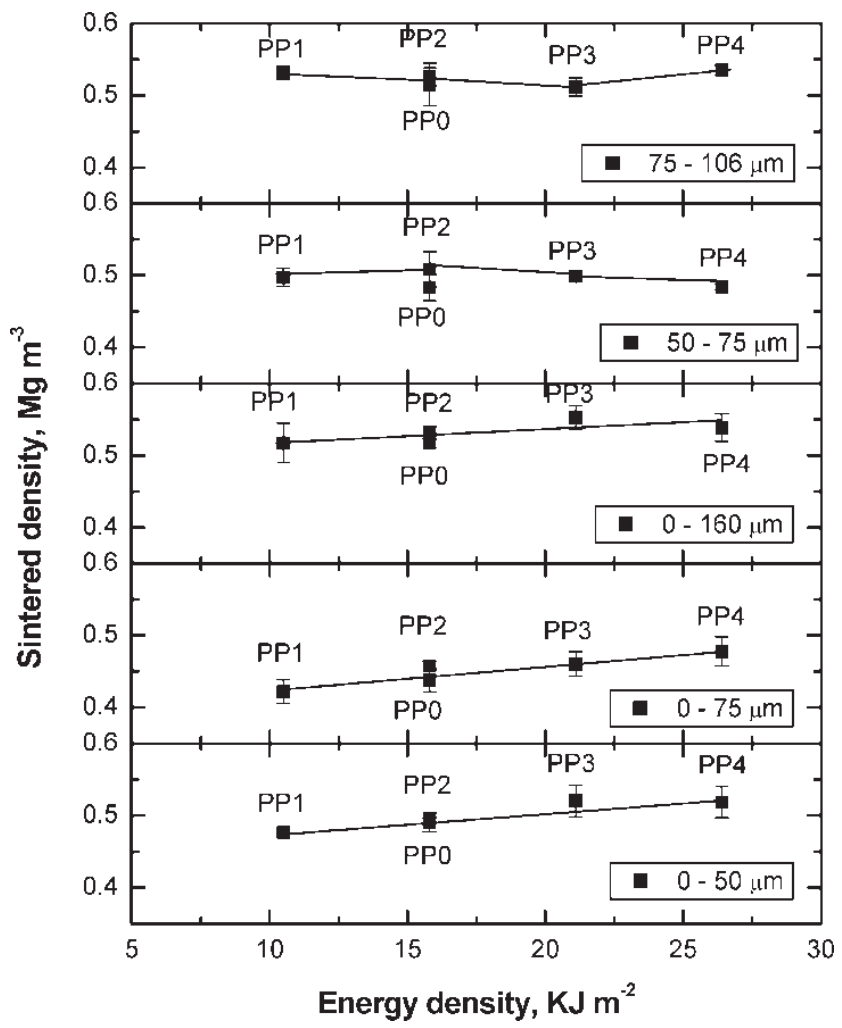

Fig. 9 The relationship between the sintered density of HA-HDPE specimens and energy density and PPs for different particle size distributions

which, in turn, would result in higher sintering activity and greater densification. The relationship between the sintered density and the PS is in agreement with the previous study, which shows that the densification kinetics in laser sintering is higher for finer iron powders. [4]. However, the specimens with the large 0-106 and 75-106 $\mu \mathrm{m}$ particles have higher sintered densities than those with small $0-50$ and $0-75 \mu \mathrm{m}$ particles. This effect is probably due to the difference in initial packing density generated for various particles during the powder deposition by rolling. The influence of the layer thickness on the density must be considered in order to investigate the effect of PS and distribution [4].

The porosity of the specimens was calculated according to equation (1)

$$
\text { Porosity }=\frac{(\text { Theoretical density }- \text { Sintered density) }}{\text { Theoretical density }}
$$

Theoretical density is calculated according to the component volume content and density of each component. (Theoretical density of HA-HDPE with $40 \mathrm{vol}$ per cent $\mathrm{HA}=40$ per cent $\times 3.162 \mathrm{Mg} / \mathrm{m}^{3}$
Table 2 Average porosity (\%) of the HA-HDPE specimens fabricated at various energy densities and PPs

\begin{tabular}{lccccc}
\hline & \multicolumn{5}{c}{ Particle size $(\mu \mathrm{m})$} \\
\cline { 2 - 6 } Laser parameter & $0-50$ & $0-75$ & $0-106$ & $50-75$ & $75-106$ \\
\hline $\mathrm{PP0}-15.8 \mathrm{~kJ} / \mathrm{m}^{2}$ & 73.1 & 76.1 & 71.7 & 72.3 & 72.7 \\
$\mathrm{PP} 1-10.5 \mathrm{~kJ} / \mathrm{m}^{2}$ & 74.0 & 76.5 & 71.8 & 72.9 & 71.1 \\
$\mathrm{PP} 2-15.8 \mathrm{~kJ} / \mathrm{m}^{2}$ & 73.0 & 75.0 & 71.0 & 73.6 & 72.1 \\
$\mathrm{PP} 3-21.1 \mathrm{~kJ} / \mathrm{m}^{2}$ & 71.5 & 74.9 & 69.9 & 72.8 & 72.3 \\
$\mathrm{PP} 4-26.4 \mathrm{~kJ} / \mathrm{m}^{2}$ & 71.8 & 74.0 & 70.6 & 73.6 & 70.8 \\
\hline
\end{tabular}

$\left(\right.$ density of HA) +60 per cent $\times 0.949 \mathrm{Mg} / \mathrm{m}^{3}$ (density of HDPE) $=1.8342 \mathrm{Mg} / \mathrm{m}^{3}$ ). Table 2 shows the average porosity of the HA-HDPE specimens fabricated at various parameters. The porosity is in the range of 69.9-76.5 per cent, showing that these specimens are highly porous.

\subsection{Interparticle connectivity and pore sizes at various PSs and PPs}

The powder sintering mechanism in the SLS process is mainly realized by liquid-phase sintering. In the case of two-component powders, the powders are sintered by joining the solid particles of the higher melting point phase using the molten binder phase that has a lower melting temperature and thus forms the liquid phase. For the compounded composite powders in which the binder is already compounded with the solid particles, the binder functions to join the composite powders. The formation of interparticle connectivity is the most critical stage of the SLS process [25]. Figure. 10 shows the process of contact formation for the composite HAHDPE powders during SLS. The heat supplied by the laser to the composite particles causes the HDPE at the surfaces to melt and thereby form interparticle connections and then surface tension draws the particles together. Assuming that the particles are spherical and regular, the initial package of small and large particles is illustrated in Fig. 11 and the PS determines the amount of surface contact between the particles. Figure 12 shows the interparticle connectivity at the surfaces of the specimens. The specimens do not show any evidence of flattened surfaces after the flow of completely melted liquid. The interparticle connectivity and sintering of the particles are more likely to depend on surface melting and joining. Small round particles, 3-10 $\mu \mathrm{m}$ across, standing protruding from the surface are HA particles, and the size of these particles is in agreement with the range of the PS of the HA used (Fig. 12(a)). Some interparticle connectivity, which appears as bridge between the particles (Fig. 12(a)), would have been formed by the melted HDPE 


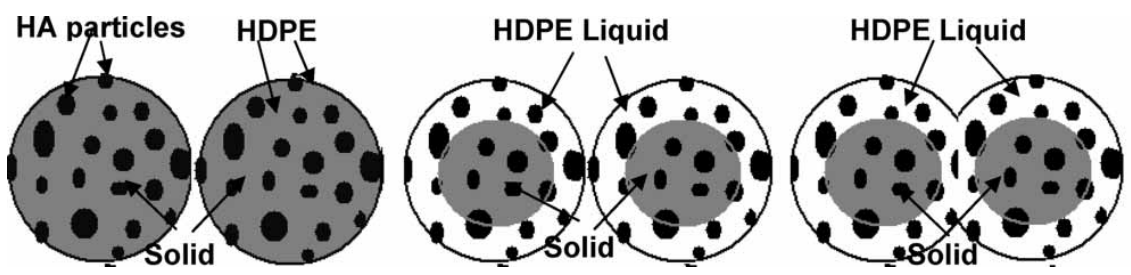

Fig. 10 Schemes of interparticle connectivity formation during SLS of compounded powders

during the laser sintering. Thus, liquid-phase sintering would have occurred in the SLS processing and the main advantage of liquid-phase sintering is the very fast initial binding, based on capillary forces, which can be very high. The small $0-50 \mu \mathrm{m}$ particles show good interparticle connectivity, and each particle fuses with the neighbouring particles. Conversely, partial interparticle connectivity is dominant in the specimens made from the $0-75$ and $0-106 \mu \mathrm{m}$ particles, whereas only a few interparticle connections are observed between the $50-75 \mu \mathrm{m}$ particles and even less interparticle connectivity is shown between the 75-106 $\mu \mathrm{m}$ particles (Fig. 12). This finding reveals that the PS and the particle distribution play a significant role in the formation of interparticle connectivity. One reason may be that the binding mechanism in the liquid-phase sintering is based on the capillary force, which is proportional to the reciprocal of the PS [26]. Thus, the smaller the initial powder size, the higher the degree of binding during liquid-phase sintering. Another reason is the larger surface area and more contact points for the smaller particles than the larger particles in the initially deposited powders (Fig. 11). The formation of the interparticle connectivity would be based on these surface areas and surface contacts. The mixture powders of small and large particles have more surface contacts than the powder of large particles only (Fig. 11). This may explain why there is more interparticle connectivity in the sintered $0-75$ and
0-106 $\mu \mathrm{m}$ powders than $50-75$ and $75-106 \mu \mathrm{m}$ powders, respectively.

As discussed earlier, the SLS specimens have highly porous structure. Pore size and interconnectivity play a significant role on the bioactivity of implants, which leads to increased rates of cell proliferation and bone ingrowth [27]. The pores were observed at the surface of the laser-fabricated specimen (Fig. 13). Pores on specimens fabricated at $6.0 \mathrm{~W}$ are smaller than those on specimens fabricated at $3.6 \mathrm{~W}$, indicating that the pore size decreases as the laser energy density increases. This finding may be explained, as the higher laser energy density resulted in better fusion of the particles and greater densification and, therefore, smaller pores remaining between the particles. The pores among the particles are also influenced by the PS. The pore size increases with the powder PS (Fig. 13). The pores formed in the specimen with 75-106 $\mu \mathrm{m}$ particles are $40-60 \mu \mathrm{m}$ when compared with the $20-30 \mu \mathrm{m}$ pores formed in the specimen with $0-50 \mu \mathrm{m}$ particles. The PS and the distribution determine the interparticle spaces in the initially deposited powders as shown in Fig. 11 and thereof influence the pores among the lasersintered specimen. Comparing the pore sizes in Fig. 12(a) with those in Figs. 12(b) and (c) implies that the PS has a greater effect on the pore size than the laser parameters within the range studied here. The size of pores among the specimens ranges from 20 to $60 \mu \mathrm{m}$, similar to the size of

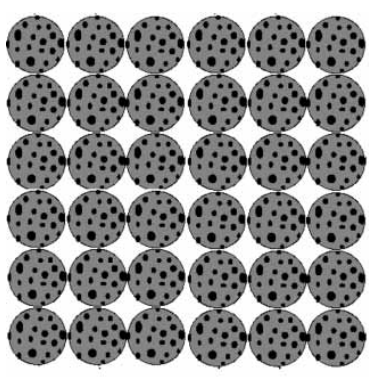

(a)

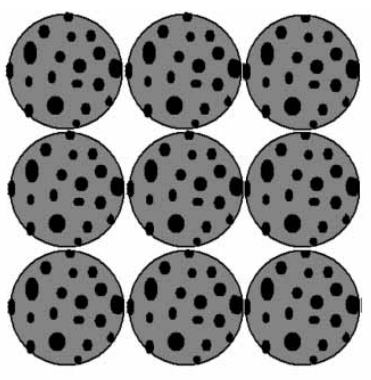

(b)

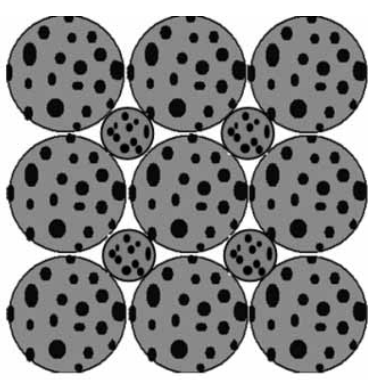

(c)

Fig. 11 Schemes of interparticle connectivity in the powders of (a) small particles, (b) large particles, and (c) the mixture of small and large particles 


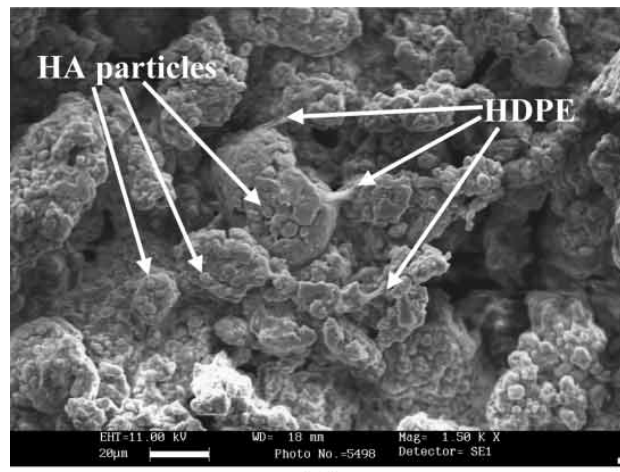

(a)

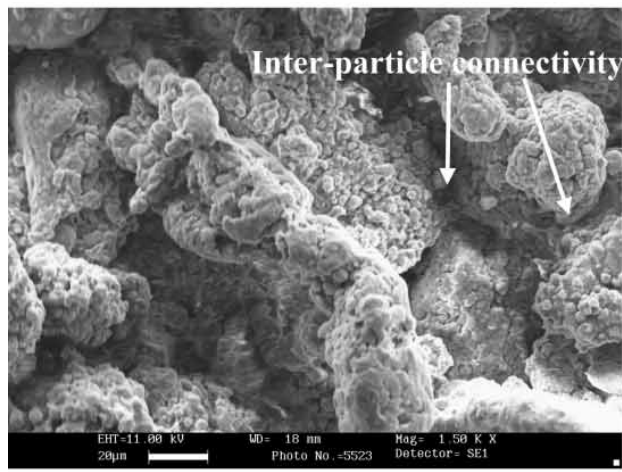

(c)

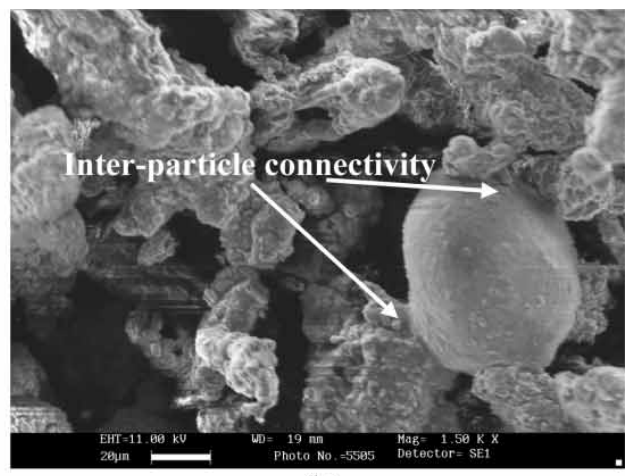

(b)

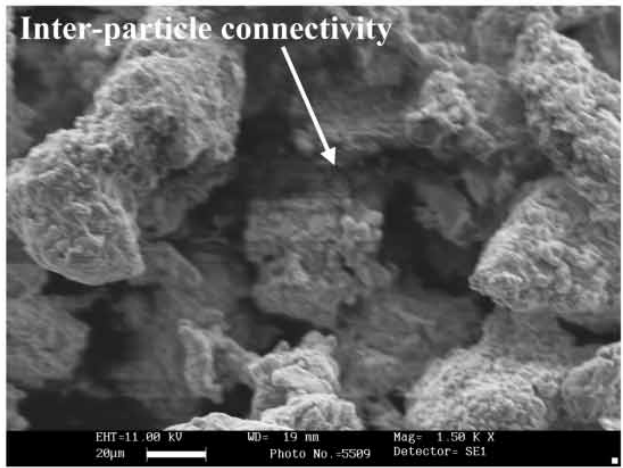

(d)

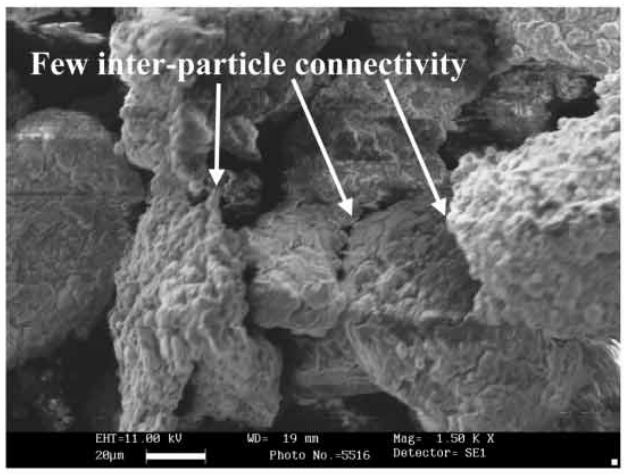

(e)

Fig. 12 SEM surface images of HA-HDPE specimens at laser power of 3.6 W and scanning speed of $3600 \mathrm{~mm} / \mathrm{s}$ using powder particles: (a) $0-50 \mu \mathrm{m}$; (b) $0-75 \mu \mathrm{m}$; (c) $0-106 \mu \mathrm{m}$; (d) 50-75 $\mu \mathrm{m}$; (e) 75-106 $\mu \mathrm{m}$ (marker bars $=20 \mu \mathrm{m}$ )

osteoblast cells after spreading [28]. Pores of this size would provide a local micro-environment for individual cells and such micro-environment presents potential biochemical, cellular, and physical stimuli that orchestrate cellular processes such as proliferation, differentiation, migration, and apoptosis [29]. Furthermore, a macro-environment that can provide sufficient nutrient and allow vascularization is essential for tissue regeneration. The minimum recommended pore size for a tissue scaffold is $100 \mu \mathrm{m}$ and some studies have shown better osteogenesis for implants with pores $>300 \mu \mathrm{m}$ [30]. To obtain large pores from 200 to $500 \mu \mathrm{m}$ [31] for vascularization and tissue regeneration, a merit of the SLS process is to fabricate designed internal structure as demonstrated by Das et al. [8] and Williams et al. [9] and is the subject of future study.

\subsection{Strength of the HA-HDPE specimens}

Owing to the highly porous structure of the specimens, the strength of most of the specimens was not sufficient for conventional mechanical testing. The strength was estimated by handling: the level of the strength is defined on the basis of the degree of care needed to avoid the fracture of the sample 


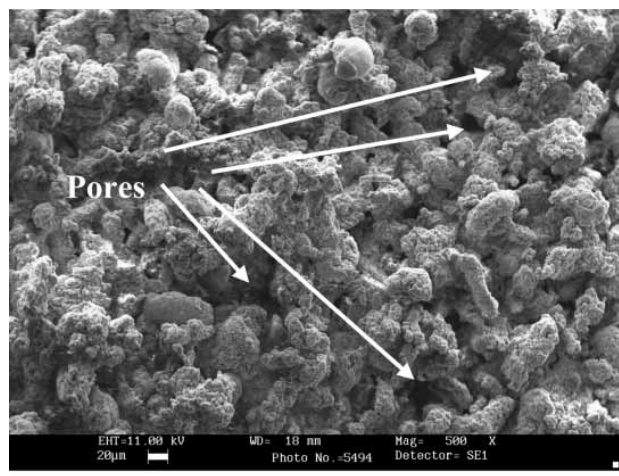

(a)

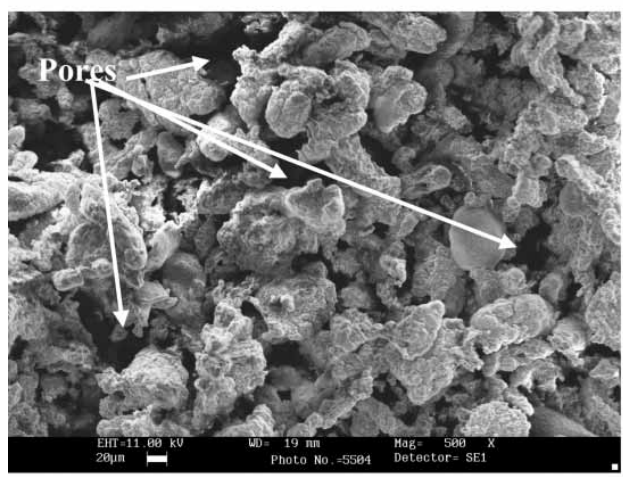

(c)

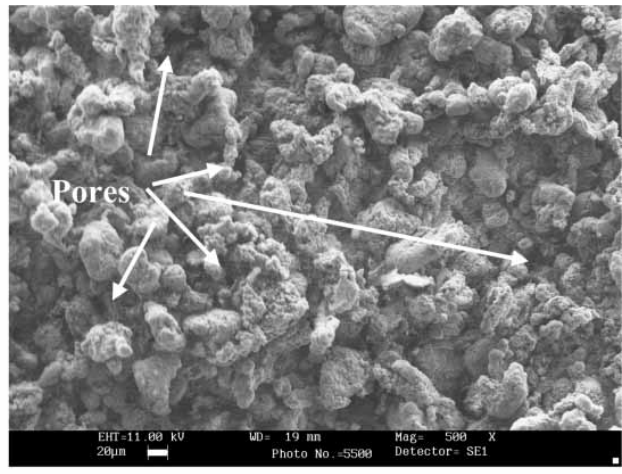

(b)

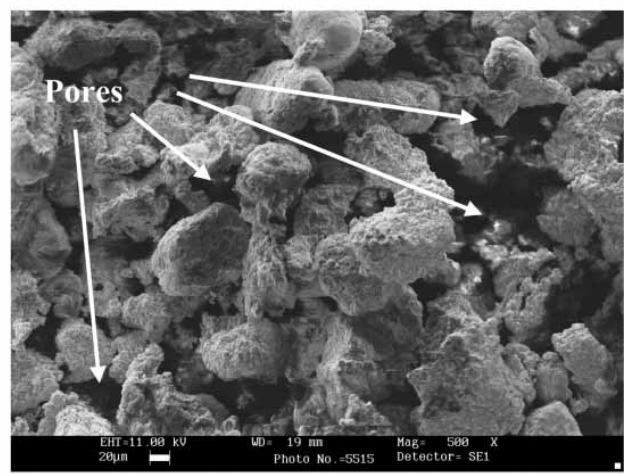

(d)

Fig. 13 SEM surface images of HA-HDPE specimens at scanning speed of $3600 \mathrm{~mm} / \mathrm{s}$ : (a) $3.6 \mathrm{~W}$, $0-50 \mu \mathrm{m}$, and (b) $6.0 \mathrm{~W}, 0-50 \mu \mathrm{m}$, and (c) $3.6 \mathrm{~W}, 0-75 \mu \mathrm{m}$, and (d) $3.6 \mathrm{~W}, 75-106 \mu \mathrm{m}$ (marker bars $=20 \mu \mathrm{m}$ )

during the handling process. The term 'low strength' indicates that the sample is easily broken without extremely careful handling. The term 'high strength' indicates that the sample is not broken with careful handling. It was also attempted to measure the strength of samples using dynamic mechanical analysis (DMA). The sample considered as having high strength presented storage modulus in the range of 10-50 MPa. Although the sample deformed substantially and the results were not very reliable, it shows that the sample with high strength could stand certain force and the storage modulus of this sample is in the range of 10-50 MPa. The sample considered as having medium strength was deformed seriously and broken after applying minimum force under
DMA. Hence, no value was obtained. The sample considered as having low strength was broken during the handling process or before applying the minimum force under DMA analysis. The strength of the sample was influenced by the PP and the particles, as shown in Table 3. In general, the strength increases with increasing laser energy density, and higher energy density results in better densification and thereby generates higher strength specimens. PS plays a predominant role in the strength of the specimens. The strength of the specimen with $0-50 \mu \mathrm{m}$ particle powders is high at PP3 and PP4 conditions, whereas powders of $75-106 \mu \mathrm{m}$ give low and medium strength specimens at PP3 and PP4 conditions, respectively.

Table 3 Strength of the HA-HDPE specimens fabricated at various PPs and PS ranges

\begin{tabular}{|c|c|c|c|c|c|}
\hline \multirow[b]{2}{*}{ Laser parameter } & \multicolumn{5}{|c|}{ Particle size $(\mu \mathrm{m})$} \\
\hline & $0-50$ & $0-75$ & $0-106$ & $50-75$ & $75-106$ \\
\hline $\mathrm{PP} 0-15.8 \mathrm{~kJ} / \mathrm{m}^{2}$ & Medium & Medium & Low & Low & Low \\
\hline $\mathrm{PP} 1-10.5 \mathrm{~kJ} / \mathrm{m}^{2}$ & Low & Low & Low & Low & Low \\
\hline $\mathrm{PP} 2-15.8 \mathrm{~kJ} / \mathrm{m}^{2}$ & Medium & Medium & Medium & Low & Low \\
\hline $\mathrm{PP} 3-21.1 \mathrm{~kJ} / \mathrm{m}^{2}$ & High & Medium & Medium & Medium & Low \\
\hline $\mathrm{PP} 4-26.4 \mathrm{~kJ} / \mathrm{m}^{2}$ & High & High & High & Medium & Medium \\
\hline
\end{tabular}


However, even the specimens with high strength still can be deformed easily after applying minimum force and broken following bending or impacting by hand, indicating the limited mechanical properties. The poor mechanical strength is attributed to the high porosity, although this higher porosity is positive because it allows more ingrowth of the bone tissue. Considering the mechanical properties, there is an upper functional limit for pore size and porosity [30]. In addition, the high HA content in the composite would provide greater bioactivity to the product; however, it means less HDPE binder and low binding strength at the interface of the particles. The use of composite powders with higher HDPE content for SLS may help to improve the mechanical properties. Thus, the HA-HDPE composites with 40 vol per cent HA fabricated by SLS without post-processing would be used in non-load bearing and low load bearing situations, such as the facial areas, where bone ingrowth would increase the mechanical strength and support the load bearing applications.

\section{CONCLUSIONS}

This study shows that the material morphology and the processing conditions play an important role in the characteristics of HA-HDPE specimens fabricated by an experimental SLS system.

The sintered height of the specimens increases with increasing laser energy density at the same scanning speed. However, the same energy density with different laser powers and scanning speeds could result in differences in the sintering height because of the different heat penetration and induction rates.

Some non-scanned powders near the laser scanning boundary were sintered because of the heat transferred from the laser scanned areas, influencing the accuracy of the specimen dimensions. The shrinkage occurred in the sintered layer and different shrinkage rates were found from the bottom to the top of the specimen. The PPs influence the accuracy of the dimension and shrinkage ratio of the specimens, whereas the characteristics of the particles play an insignificant role.

The higher laser energy density generates higher sintered density for the specimens with small particles of $0-50$ and $0-75 \mu \mathrm{m}$ size ranges. The porosity was from 69.9 to 76.5 per cent for these specimens, showing that they are highly porous structures.

PS plays a significant role in the formation of interparticle connectivity. The smaller particles resulted in the better formation of interparticle connectivity and smaller surface pores. Higher energy density caused greater densification and smaller pore size.
The strength of the sample was influenced by the PPs and the PS. The specimens fabricated using small particles and high energy density present the highest strength. The poor mechanical strength was attributed to the high porosity and would restrict the application of SLS-fabricated HA-HDPE to non-load bearing situations.

\section{ACKNOWLEDGEMENTS}

The authors would like to express their gratitude for financial support from the UK Department of Health's New and Emerging Applications of Technology (NEAT E059) programme.

\section{REFERENCES}

1 Kruth, J. P., Wang, X., Laoui, T., and Froyen, L. Lasers and materials in selective laser sintering. Assembly Autom., 2003, 23, 357-371.

2 Gibson, I. and Shi, D. Material properties and fabrication parameters in selective laser sintering process. Rapid Prototyping J., 1997, 3, 129-136.

3 Simchi, A. and Pohl, H. Effects of laser sintering processing parameters on the microstructure and densification of iron powder. Mater. Sci. Eng. A, 2003, 359, 119-128.

4 Simchi, A. The role of particle size on the laser sintering of iron powder. Metall. Mater. Trans. B, 2004, 35, 937-948.

5 Shi, Y., Li, Z., Sun, H., Huang, S., and Zeng, F. Effect of the properties of the polymer materials on the quality of selective laser sintering parts. Proc. Instn Mech. Engrs, Part L: J. Materials: Design and Applications, 2004, 218, 247-252.

6 Hing, K. A., Best, S. M., Tanner, K. E., Bonfield, W., and Revell, P. A. Mediation of bone ingrowth in porous hydroxyapatite bone graft substitutes. J. Biomed. Mater. Res. A, 2004, 68A, 187-200.

7 Vail, N. K., Swain, L. D., Fox, W. C., Aufdlemorte, T. B., Lee, G., and Barlow, J. W. Materials for biomedical applications. Mater. Des., 1999, 20, 123-132.

8 Das, S., Hollister, S. J., Flanagan, C., Adewunmi, A., Bark, K., Chen, C., Ramaswamy, K., Rose, D., and Widjaja, E. Computational design, freeform fabrication and testing of nylon-6 tissue engineering scaffolds. Rapid Prototyping Technologies, Boston, MA, USA, 35 December 2002, 2003, pp. 205-210.

9 Williams, J. M., Adewunmi, A., Schek, R. M., Flanagan, C. L., Krebsbach, P. H., Feinberg, S. E., Hollister, S. J., and Das, S. Bone tissue engineering using polycaprolactone scaffolds fabricated via selective laser sintering. Biomaterials, 2005, 26, 4817-4827.

10 Tan, K. H., Chua, C. K., Leong, K. F., Cheah, C. M., Cheang, P., Abu Bakar, M. S., and Cha, S. W. Scaffold development using selective laser sintering of polyetheretherketone-hydroxyapatite biocomposite blends. Biomaterials, 2003, 24, 3115-3123. 
11 Chua, C. K., Leong, K. F., Tan, K. H., Wiria, F. E., and Cheah, C. M. Development of tissue scaffolds using selective laser sintering of polyvinyl alcohol/hydroxyapatite biocomposite for craniofacial and joint defects. J. Mater. Sci. Mater. Med., 2004, 15, 1113-1121.

12 Cruz, F., Simoes, J., Coole, T., and Bucking, T. Direct manufacturing of hydroxyapatite based bone implants by selective laser sintering. 2nd International Conference on Advanced research in virtual and rapid prototyping, Leiria, Portugal, 2005, pp. 119-125.

13 Leong, K. F., Phua, K. K. S., Chua, C. K., Du, Z. H., and Teo, K. O. M. Fabrication of porous polymeric matrix drug delivery devices using the selective laser sintering technique. Proc. Instn Mech. Engrs, Part H: J. Engineering in Medicine, 2001, 215, 191-201.

14 Low, K. H., Leong, K. F., Chua, C. K., Du, Z. H., and Cheah, C. M. Characterization of SLS parts for drug delivery devices. Rapid Prototyping J., 2001, 7, 262-267.

15 Cheah, C. M., Leong, K. F., Chua, C. K., Low, K. H., and Quek, H. S. Characterization of microfeatures in selective laser sintered drug delivery devices. Proc. Instn Mech. Engrs, Part H: J. Engineering in Medicine, 2002, 216, 369-383.

16 Bonfield, W., Grynpas, M. D., Tully, A. E., Bowman, J., and Abram, J. Hydroxyapatite reinforced polyethylene a mechanically compatible implant material for bonereplacement. Biomaterials, 1981, 2, 185-186.

17 Bonfield, W., Doyle, C., and Tanner, K. E. In vivo evaluation of hydroxyapatite reinforced polyethylene composites. Biological and Biomechanical Performance of Biomaterials, Proceedings of the Fifth European Conference on Biomaterials, Paris, France, 1986, pp. $153-158$.

18 Tanner, K. E., Downes, R. N., and Bonfield, W. Clinicalapplications of hydroxyapatite reinforced materials. $\mathrm{Br}$. Ceram. Trans., 1994, 93, 104-107.

19 Savalani, M. M., Hao, L., and Harris, R. A. Evaluation of $\mathrm{CO}_{2}$ and Nd:YAG lasers for the selective laser sintering of HAPEX. Proc. IMechE, Part B: J. Engineering Manufacture, 2006, 220(B2), 171-182.

20 Wang, M., Porter, D., and Bonfield, W. Processing, characterization, and evaluation of hydroxyapatite reinforced polyethylene composites. Br. Ceram. Trans., 1994, 93, 91-95.
21 Ho, H. C. H., Gibson, I., and Cheung, W. L. Effects of energy density on morphology and properties of selective laser sintered polycarbonate. J. Mater. Process. Technol., 1999, 89-90, 204-210.

22 Hao, L., Savalani, M. M., and Harris, R. A. Layer manufacturing of polymer/bioceramic implants for bone replacement and tissue growth. Proceedings of the 2nd International Conference on Advanced research in virtual and rapid prototyping, Leiria, Portugal, 2005, pp. 127-132.

23 Yang, H.-J., Hwang, P.-J., and Lee, S.-H. A study on shrinkage compensation of the SLS process by using the Taguchi method. Int. J. Mach. Tools Manuf., 2002, 42, 1203-1212.

24 Williams, J. D. and Dechard, C. R. Advances in modeling the effects of selected parameters on the SLS process. Rapid Prototyping J., 1998, 4, 90-100.

25 Tolochko, N., Mozzharov, S., Laoui, T., and Froyen, L. Selective laser sintering of single- and two-component metal powders. Rapid Prototyping J., 2003, 9, 68-78.

26 Zhou, Y., Hirao, K., Yamauchi, Y., and Kanzaki, S. Effects of heating rate and particle size on pulse electric current sintering of alumina. Scr. Mater., 2003, 48, 1631-1636.

27 Yokozeki, H., Hayashi, T., Nakagawa, T., Kurosawa, H., Shibuya, K., and Ioku, K. Influence of surface microstructure on the reaction of the active ceramics in vivo. J. Mater. Sci. Mater. Med., 1998, 9, 381-384.

28 Hao, L., Lawrence, J., and Chian, K. S. On the effects of $\mathrm{CO}_{2}$ laser irradiation on the surface properties of a magnesia partially stabilised zirconia (MgO-PSZ) bioceramic and the subsequent improvements in human osteoblast cell adhesion. J. Biomater. Appl., 2004, 19, 81-105.

29 Liu Tsang, V. and Bhatia, S. N. Three-dimensional tissue fabrication. Adv. Drug Deliv. Rev., 2004, 56, 1635-1647.

30 Karageorgiou, V. and Kaplan, D. Porosity of 3D biomaterial scaffolds and osteogenesis. Biomaterials, 2005, 26, 5474-5491.

31 Xiong, Z., Yan, Y., Zhang, R., and Sun, L. Fabrication of porous poly(-lactic acid) scaffolds for bone tissue engineering via precise extrusion. Scr. Mater., 2001, 45, 773-779. 